\title{
Thermal Conductivity of Highly-Ordered Mesoporous Titania Thin Films from 30 to $320 \mathrm{~K}$
}

\author{
Jin Fang, ${ }^{\dagger}$ Christian Reitz, $_{\S}^{\ddagger}$ Torsten Brezesinski, $^{\ddagger}$ E. Joseph Nemanick, ${ }^{\S}$ Chris B. Kang, ${ }^{\S}$ \\ Sarah H. Tolbert, ${ }^{\S}$ and Laurent Pilon ${ }^{*,+}$ \\ ${ }^{\dagger}$ Henry Samueli School of Engineering and Applied Science Mechanical and Aerospace Engineering Department, \\ University of California, Los Angeles, California 90095-1597, United States \\ ${ }^{\ddagger}$ Giessen Institute of Physical Chemistry, Justus-Liebig-University, Heinrich-Buff Ring 58, Giessen 35392, Germany \\ ${ }^{\S}$ Department of Chemistry and Biochemistry, University of California, Los Angeles, 607 Charles E. Young Drive East, \\ Box 951569 Los Angeles, California 90095-1569, United States
}
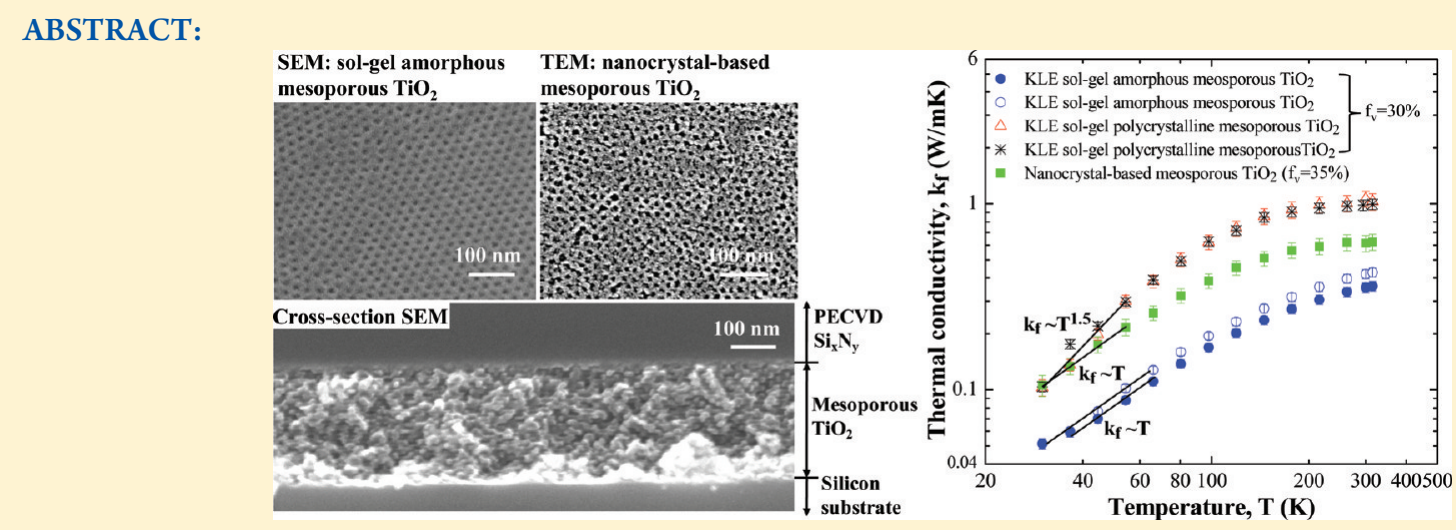

This paper reports the cross-plane thermal conductivity of highly ordered amorphous and crystalline templated mesoporous titania thin films measured by the $3 \omega$ method from 30 to $320 \mathrm{~K}$. Both sol-gel and nanocrystal-based films were synthesized by evaporationinduced self-assembly, with average porosity of $30 \%$ and $35 \%$, respectively. The pore diameter ranged from 14 to $25 \mathrm{~nm}$. The size of crystalline domains in polycrystalline mesoporous films were $12-13 \mathrm{~nm}$, while the nanocrystals in the nanocrystal-based film were $9 \mathrm{~nm}$ in diameter. At high temperatures, the thermal conductivity of amorphous dense and mesoporous films showed similar trends with respect to temperature. This was attributed to the fact that the presence of pores had a purely geometrical effect by reducing the cross-sectional area through which heat can diffuse. By contrast, the thermal conductivity of polycrystalline dense and mesoporous films behaves differently with temperature due to phonon scattering by pores and crystalline nanosize domains. In addition, at low temperatures, the presence of pores caused the thermal conductivity of mesoporous films to be less temperature dependent than their dense counterparts. Despite its crystallinity, the thermal conductivity of the nanocrystal-based film was about $40 \%$ less than that of the polycrystalline mesoporous films. This was mainly attributed to its larger porosity, smaller crystal size, and strong phonon scattering at the poorly interconnected nanocrystal boundaries. These results suggest various ways to control the thermal conductivity of mesoporous materials for various applications.

\section{INTRODUCTION}

Mesoporous titania $\left(\mathrm{TiO}_{2}\right)$ thin films have been considered for energy storage applications such as accumulators and electrochemical capacitors. ${ }^{1,2}$ They are also used as electrodes in dyesensitized solar cells $s^{3,4}$ and as high proton conductivity porous exchange membranes in solid oxide fuel cells. ${ }^{5}$ Moreover, Choi et al. ${ }^{6}$ identified mesoporous $\mathrm{TiO}_{2}$ thin films as promising thermal insulating materials for infrared sensors. Finally, other applications include (i) highly specific chemical sensors and membranes, ${ }^{7}$ (ii) photocatalyst for water and air purification, ${ }^{8,9}$ and (iii) optical coatings, emissive displays, and optoelectronics. ${ }^{10}$

Knowledge of thermal properties of mesoporous titania thin films is essential to their practical implementation into devices. ${ }^{11-14}$
A few studies reported the thermal conductivity of dense (nonporous) amorphous and crystalline $\mathrm{TiO}_{2}$ films between 80 and $400 \mathrm{~K}^{15-18}$ As for porous $\mathrm{TiO}_{2}$ thin films, Choi et al. ${ }^{6}$ measured the thermal conductivity of $250 \mathrm{~nm}$ thick amorphous templated hexagonal mesoporous $\mathrm{TiO}_{2}$ thin films at room temperature. The authors concluded that the presence of nanoscale pores reduced the thermal conductivity by a factor of 11 compared with that of nonporous crystalline $\mathrm{TiO}_{2}{ }^{6}$ Unfortunately, the authors did not report the film porosity and pore size. In addition,

\section{Received: April 12, 2011}

Revised: June 5, 2011 
Feng et al. ${ }^{19}$ reported the effective thermal diffusivity, cross-plane thermal conductivity, and density at room temperature of porous anatase $\mathrm{TiO}_{2}$ thin films with thicknesses around $60 \mu \mathrm{m}$ made of randomly oriented nanofibers. Here also, porosity remained unknown. The effective thermal conductivity of these porous $\mathrm{TiO}_{2}$ thin films was about 1 order of magnitude smaller than that of bulk dense anatase $\mathrm{TiO}_{2} \cdot{ }^{19}$ The authors indicated that the length and diameter of the nanofibers had no effect on the films effective thermal conductivity. ${ }^{19}$ Recently, Coquil et al..$^{20}$ reported the crossplane thermal conductivity at room temperature of highly ordered sol-gel and nanocrystal-based mesoporous $\mathrm{TiO}_{2}$ thin films synthesized by evaporation-induced self-assembly, with average porosity of $30 \%$ and $35 \%$, various values of pore diameter $(7-30 \mathrm{~nm})$, and film thickness $(60-370 \mathrm{~nm})$. The authors attributed the smaller thermal conductivity of amorphous thin films to the fact that heat was carried by very localized nonpropagating vibrational modes. They also showed that the thermal conductivity can be tuned by controlling the porosity as well as the connectivity and size of the nanocrystals or of the crystalline domains. However, only room temperature results were reported.

The present study aims to (i) measure the effective cross-plane thermal conductivity of mesoporous $\mathrm{TiO}_{2}$ thin films with various nanoscale architectures and (ii) investigate the effects of temperature, presence of pores, and crystallinity of the $\mathrm{TiO}_{2}$ matrix over the temperature range from 30 to $320 \mathrm{~K}$.

\section{METHOD AND EXPERIMENTS}

2.1. Mesoporous Titania Thin Film Synthesis. Synthesis of both nonporous and highly ordered amorphous and crystalline cubic mesoporous $\mathrm{TiO}_{2}$ thin films investigated in the present study were described in detail in ref 20 . The synthesis was based on calcination of polymer/titania composites produced by evaporation-induced self-assembly using the organic template poly(ethylene-co-butylene) ${ }_{89}$-block-poly(ethylene oxide) ${ }_{79}$, also referred to as KLE. ${ }^{21-23}$ In addition, two types of mesoporous titania thin films were synthesized, namely, sol-gel derived films and nanocrystal-based (NC-based) films using methods reported by Fattakhova-Rohlfing et al. ${ }^{21}$ and Brezesinski et al., ${ }^{2}$ respectively. Finally, nontemplated amorphous and crystalline $\mathrm{TiO}_{2}$ thin films were prepared by a procedure similar to that used to synthesize the mesoporous sol-gel films but without any organic template. The nontemplated films are also referred to as dense samples in order to distinguish them from the copolymertemplated mesoporous ones. However, note that the sol-gel derived nontemplated films were not fully dense but slightly porous. ${ }^{24}$ Finally, the crystalline phase was anatase in all cases.

2.2. Characterization. Characterization of the films investigated in the present study has been reported in detail by Coquil et al. ${ }^{20}$ It included one- and two-dimensional small-angle X-ray scattering (1D-SAXS and 2D-SAXS), scanning and transmission electron microscopy (SEM and TEM), and wide-angle X-ray diffraction (WAXD) measurements. ${ }^{20}$ In brief, parts $\mathrm{a}$ and $\mathrm{b}$ of Figure 1 show SEM micrographs of KLE-templated sol-gel amorphous and of crystalline (anatase) mesoporous $\mathrm{TiO}_{2}$ thin films, respectively. ${ }^{20}$ These micrographs confirmed the highly ordered mesoporous structure of the films. The KLE templated sol-gel mesoporous $\mathrm{TiO}_{2}$ thin films consisted of ellipsoidal pores of in-plane diameter $14-19 \mathrm{~nm}$ organized in bcc lattice with a porosity of $30 \%$. Moverover, the KLE-templated sol-gel films showed similar pore dimensions in crystalline and amorphous states as also observed by Fattakhova-Rohlfing et al. ${ }^{21}$
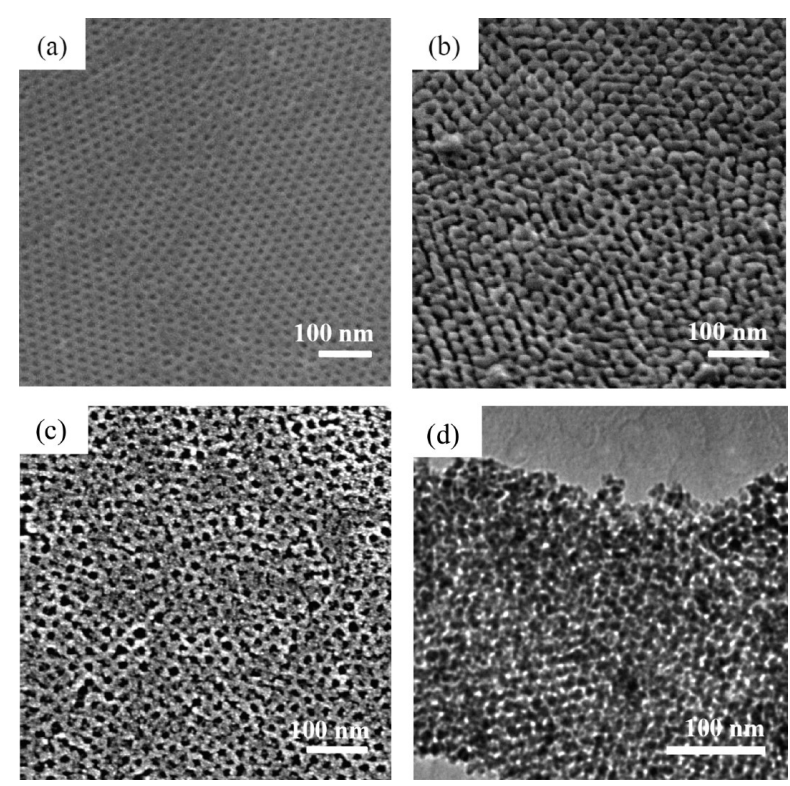

Figure 1. SEM micrographs of KLE-templated sol-gel derived (a) amorphous and (b) crystalline mesoporous $\mathrm{TiO}_{2}$ and (c) SEM and (d) TEM micrographs of nanocrystal-based mesoporous $\mathrm{TiO}_{2}$ thin films also templated using KLE-based diblock copolymers. ${ }^{20}$.

Parts $\mathrm{c}$ and $\mathrm{d}$ of Figure 1 respectively show SEM and bright field TEM micrographs of the disordered but macroscopically homogeneous architecture of NC-based mesoporous $\mathrm{TiO}_{2}$ films made of anatase nanocrystals about $9 \mathrm{~nm}$ in size and featuring pores $17-25 \mathrm{~nm}$ in diameter. Note that the dense crystalline sol-gel type $\mathrm{TiO}_{2}$ thin films featured crystalline domains about $30 \mathrm{~nm}$ in diameter. Table 1 summarizes the crystallinity, porosity, film thickness, pore diameter, wall thickness, and crystal size of the $\mathrm{TiO}_{2}$ thin films investigated.

2.3. Experimental Setup. The cross-plane thermal conductivity of highly ordered mesoporous $\mathrm{TiO}_{2}$ thin films was measured using the $3 \omega$ method. ${ }^{25}$ The principles, microfabrication of the test section metallic pattern, and validation of the $3 \omega$ method at room temperature have already been described in detail elsewhere $^{26}$ and need not be repeated. Briefly, a thin silicon nitride $\left(\mathrm{Si}_{x} \mathrm{~N}_{y}\right)$ layer was first deposited on the sample films by plasma-enhanced chemical vapor deposition (PECVD) in order to (i) protect the mesoporous structure of the samples and (ii) act as an electrically insulating layer. Meanwhile, a nitride layer with identical thickness was also deposited on a bare silicon substrate in the same batch as the samples and served as a reference. Note that this PECVD passivation process has also been used as an effective method to seal various porous thin films. ${ }^{27-30}$ In fact, Figure 2 shows a cross-section SEM micrograph of our mesoporous $\mathrm{TiO}_{2}$ films. It establishes that only the open pores located at the surface of the film were filled with $\mathrm{Si}_{x} \mathrm{~N}_{y}$. Their diameter represents a very small fraction of the film thickness. Then, the metallic wire made of $10 \mathrm{~nm}$ thick $\mathrm{Cr}$ and $100-150 \mathrm{~nm}$ thick $\mathrm{Al}$ was deposited on both the sample and the reference by a standard lift-off process. It was $30 \mu \mathrm{m}$ wide and $1 \mathrm{~mm}$ long and served both as heater and sensor. The metallic pattern was then connected to the measuring circuit using wire bonding technique. To do so, one end of an aluminum wire was first connected to the sample carrier by ultrasonic wire bonding. Then, the other end of the wire was carefully attached to the metallic pattern using silver epoxy. Finally, the sample and its 
Table 1. Characteristics of the Mesoporous Titania Thin Films Investigated

\begin{tabular}{|c|c|c|c|c|c|c|c|}
\hline sample no. & crystallinity & process & porosity, $f_{\mathrm{v}}( \pm 2 \%)$ & thickness, $t_{\mathrm{f}}(\mathrm{nm})$ & pore diameter, $d(\mathrm{~nm})$ & wall thickness, $t_{\mathrm{wall}}(\mathrm{nm})$ & crystal size $(\mathrm{nm})$ \\
\hline 1 & amorphous & sol-gel & $0 \%$ & 120 & - & - & - \\
\hline 2 & polycrystalline $^{b}$ & sol-gel & $0 \%$ & 150 & - & - & 30 \\
\hline 3 & amorphous & sol-gel & $30 \%$ & 250 & $14-19$ & $8-12$ & - \\
\hline 4 & amorphous & sol-gel & $30 \%$ & 300 & $14-19$ & $8-12$ & - \\
\hline 5 & polycrystalline $^{b}$ & sol-gel & $30 \%$ & 260 & $14-19$ & $8-12$ & $12-13$ \\
\hline 6 & polycrystalline $e^{b}$ & sol-gel & $30 \%$ & 370 & $14-19$ & $8-12$ & $12-13$ \\
\hline 7 & polycrystalline $e^{b}$ & $\mathrm{NC}^{- \text {based }^{a}}$ & $35 \%$ & 160 & $17-25$ & $15-25$ & 9 \\
\hline
\end{tabular}



Figure 2. Cross-section SEM micrograph of a typical mesoporous $\mathrm{TiO}_{2}$ sample film protected with a PECVD $\mathrm{Si}_{x} \mathrm{~N}_{y}$ layer.

carrier together were baked at $65{ }^{\circ} \mathrm{C}$ for $4 \mathrm{~h}$ to ensure good electrical conductivity.

Figure 3 shows the schematic of the experimental setup. It consisted of a thermal subsystem and an electrical subsystem. The thermal subsystem consisted of a coldfinger cryostat (model ST100 from Janis Research Company, Inc.), a helium dewar, and a temperature controller (model 331s from Lake Shore Cryotronics, Inc.) used to control the temperature with $\pm 0.1 \mathrm{~K}$ accuracy. The cryostat space was evacuated to a pressure less than $1 \mathrm{mtorr}$ in order to minimize heat losses by conduction and convection. In order to minimize sample temperature rise due to Joule heating in the metallic wire, cryogenic thermal grease was applied to the interface between the sample's substrate and the cryostat coldfinger. The rise in sample temperature above the cryostat set temperature was estimated to be less than $5 \mathrm{~K}$ for $T<$ $100 \mathrm{~K}$ and less than $2 \mathrm{~K}$ for $T>100 \mathrm{~K}$. The electrical subsystem used a lock-in amplifier (model SR830 from Stanford Research Systems, Inc.) to measure the third harmonic voltage response from the metallic wire. ${ }^{26}$

2.4. Experimental Procedure. Thermal conductivity measurements were divided into two steps. First, the temperature of the metallic heater was calibrated, and its temperature-dependent electrical resistance $R_{\mathrm{e}}(T)$ was measured. To do so, a small ac voltage (around $0.1 \mathrm{~V}_{\mathrm{rms}}$ ) was supplied to the metallic heater to measure its electrical resistance $R_{\mathrm{e}}(T)$ between 30 and $320 \mathrm{~K}$. Second, the cross-plane thermal conductivity of the sample film was measured for a given temperature. To do so, a large ac voltage (around $0.5 \mathrm{~V}_{\mathrm{rms}}$ ) was applied to the metallic heater at different frequencies. The third harmonic voltage drop $V_{3 \omega}$ across the metallic heater was collected by the lock-in amplifier with a $2 \%$ relative uncertainty for each frequency. As suggested by Cahill, ${ }^{25}$ the frequency range was chosen such that (i) the inphase component of the amplitude of $V_{3 \omega}$ decreased linearly with the logarithm of frequency and (ii) the out-of-phase component

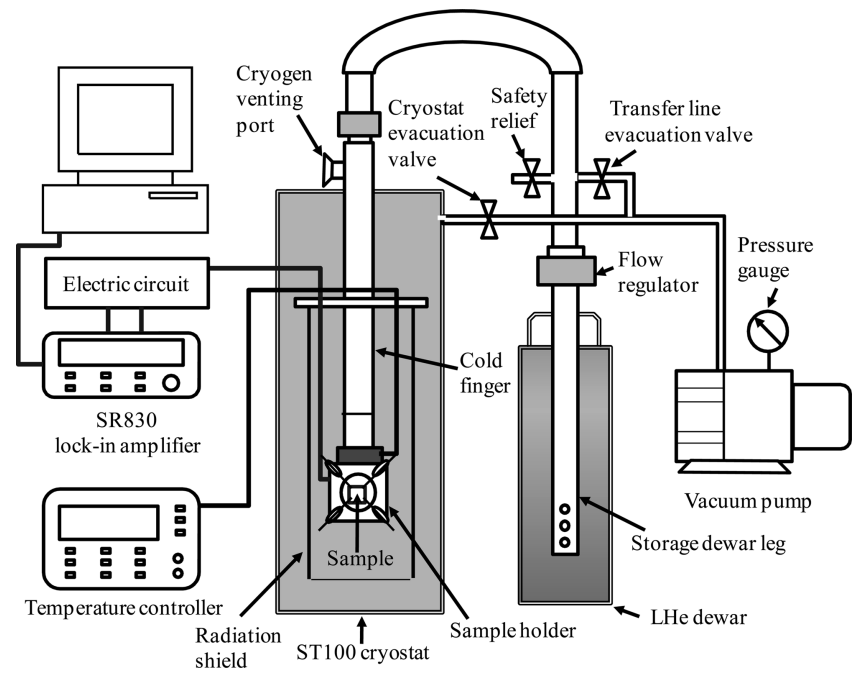

Figure 3. Experimental setup used for thin film thermal conductivity measurements between 30 and $320 \mathrm{~K}$.

of the amplitude of $V_{3 \omega}$ was nearly independent of frequency. In the present study, the typical frequency range considered was from 0.4 to $2.0 \mathrm{kHz}$. The temperature oscillation amplitude $\Delta T$ was then determined from the third harmonic voltage $V_{3 \omega}$ according to ${ }^{25}$

$$
\Delta T=\frac{2 V_{3 \omega} R_{\mathrm{e}}}{V_{\omega}\left(\mathrm{d} R_{\mathrm{e}} / \mathrm{d} T\right)}
$$

where $V_{\omega}$ is the applied first harmonic ac voltage measured by a multimeter (Agilent 34401a) while $\mathrm{d} R_{\mathrm{e}} / \mathrm{d} T$ is the derivative of the electrical resistance of the heater with respect to temperature.

A large contribution to the uncertainty of $\Delta T$ given by eq 1 is due to the uncertainty associated with $\mathrm{d} R_{\mathrm{e}} / \mathrm{d} T$. For small temperature range, a linear relationship between $R_{\mathrm{e}}$ and $T$ can be used to fit the data. ${ }^{26}$ However, large error is expected when fitting data with a linear function over a wide temperature range. Instead, the Bloch-Grüneisen $(B-G)$ model $^{31}$ was used, in the present study, to fit $R_{\mathrm{e}}(T)$ between 30 and $320 \mathrm{~K}$ as performed by Chen et al. ${ }^{32}$ The $\mathrm{B}-\mathrm{G}$ model is expressed as ${ }^{31}$

$$
R_{\mathrm{e}, \mathrm{B}-\mathrm{G}}(T)=A+B\left(\frac{T}{C}\right)^{5} \int_{0}^{C / T} \frac{x^{5}}{\left(\mathrm{e}^{x}-1\right)\left(1-\mathrm{e}^{-x}\right)} \mathrm{d} x
$$

where $A, B$, and $C$ are three empirical parameters. These parameters were obtained, for each film, by fitting eq 2 to experimental data for $R_{\mathrm{e}}(T)$ using the simplex method. ${ }^{33}$ Figure 4 shows the typical electrical resistance of a metallic heater as a 


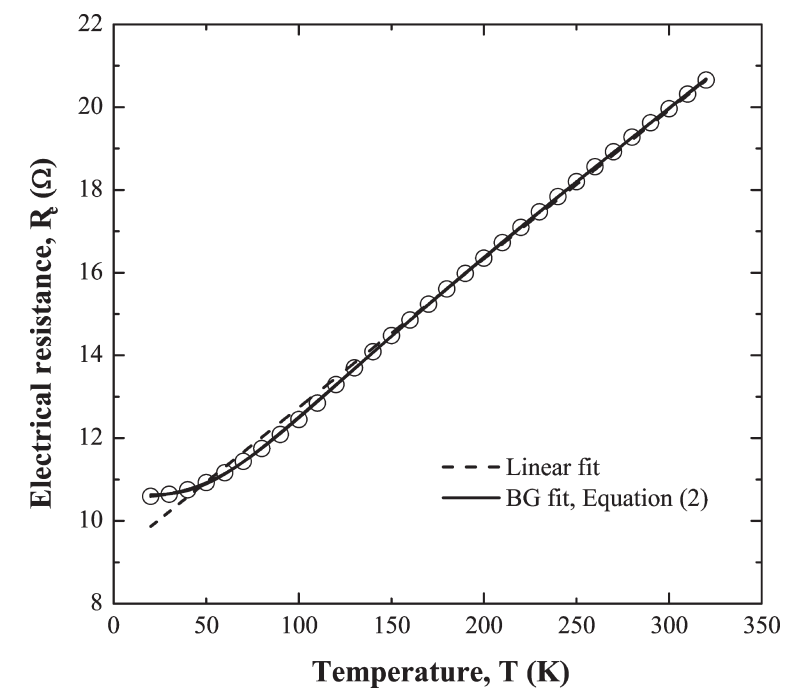

Figure 4. Typical electrical resistance of a metallic heater along with linear fitting (dashed line) and $\mathrm{B}-\mathrm{G}$ model fitting (solid line) given by eq 2 for $A=10.62 \Omega, B=45.17 \Omega$, and $C=337.8 \mathrm{~K}$.

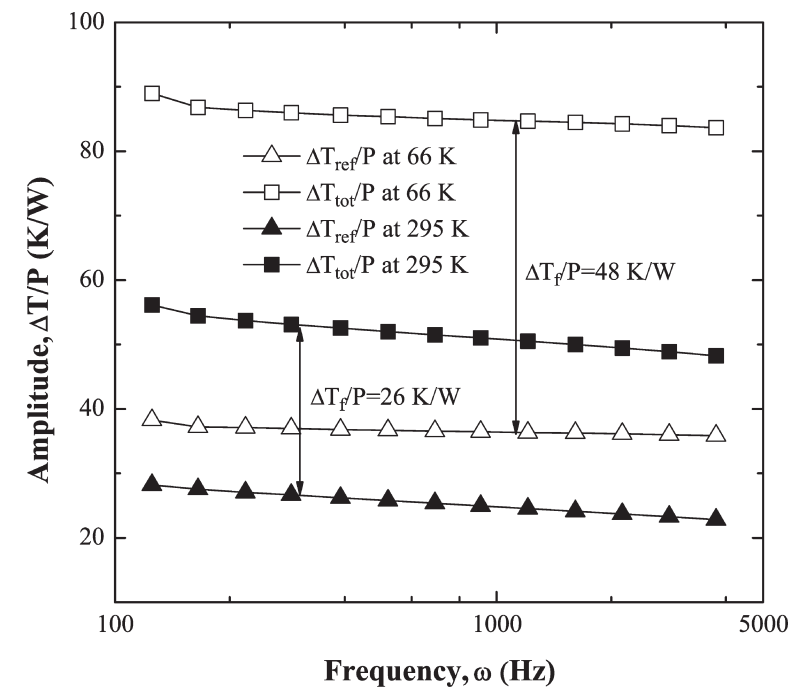

Figure 5. Example of amplitude of temperature oscillation per unit power $\Delta T_{\text {ref }} / P$ and $\Delta T_{\text {tot }} / P$ as a function of frequency at temperatures 66 and $295 \mathrm{~K}$. function of temperature. It indicates that the fitted $B-G$ model gave better prediction of the experimental data than linear curve fitting for $A=10.62 \Omega, B=45.17 \Omega$, and $C=337.8 \mathrm{~K}$. The relative difference $\varepsilon$ between experimental measurement and prediction by the fitting model is defined as $\varepsilon=\left[R_{\mathrm{e}, \mathrm{fit}}(T)-R_{\mathrm{e}}(T)\right] / R_{\mathrm{e}}(T)$, where $R_{\mathrm{e}, \mathrm{fit}}(T)$ is the fitted value at temperature $T$ obtained either by linear fit or using the $\mathrm{B}-\mathrm{G}$ model. Here, $\varepsilon$ associated with the $\mathrm{B}-\mathrm{G}$ model was less than $0.5 \%$ for all temperatures. For the linear fit, $\varepsilon$ was larger than $0.5 \%$ and reached up to $4 \%$ for $T<150 \mathrm{~K}$. Finally, the derivative of the electrical resistance with respect to temperature $\mathrm{d} R_{\mathrm{e}} / \mathrm{d} T$ used in eq 1 was calculated by applying centered difference method to the $\mathrm{B}-\mathrm{G}$ fitted curve.

Finally, the differential $3 \omega$ method was used to analyze the data. ${ }^{34}$ The amplitude of temperature oscillations in the mesoporous thin film $\Delta T_{\mathrm{f}}$ was calculated by subtracting the amplitude of temperature oscillation of the reference nitride film $\Delta T_{\text {ref }}$ from

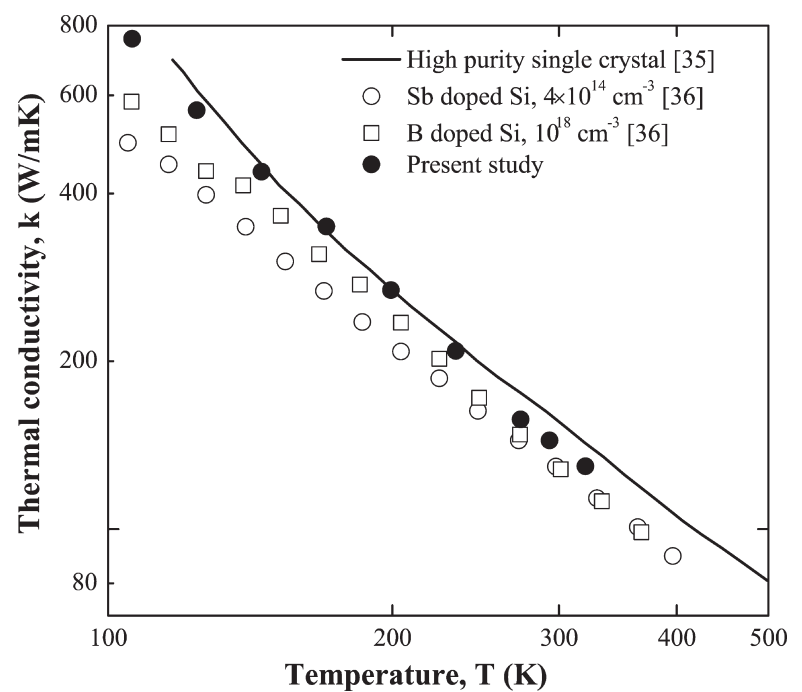

Figure 6. Measured thermal conductivity of high purity single crystal silicon substrate as a function of temperature along with data reported in the literature for high purity and Sb- and B-doped single crystal silicon. ${ }^{35,36}$

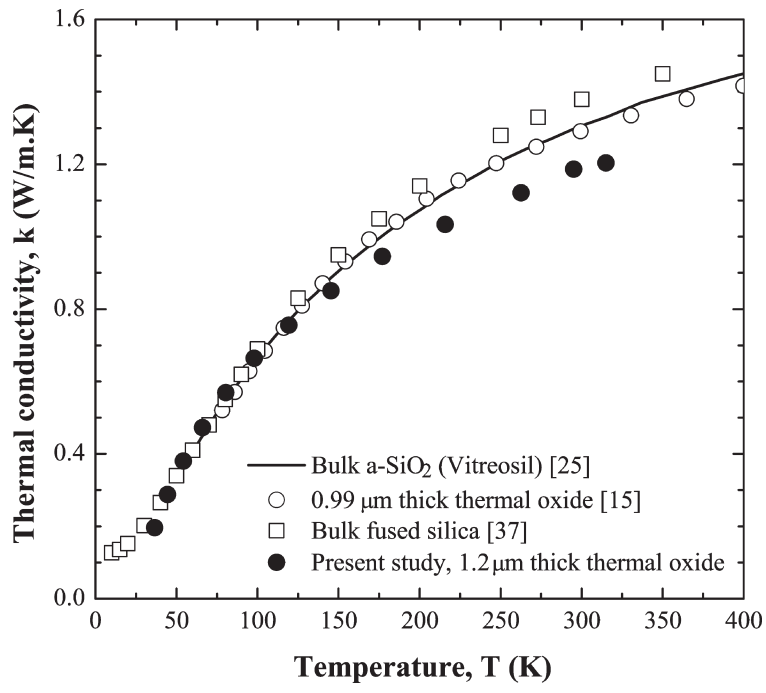

Figure 7. Measured thermal conductivity of $1.2 \mu \mathrm{m}$ thick thermal oxide film as a function of temperature between 30 and $320 \mathrm{~K}$ along with previously reported data. ${ }^{15,25,37}$

that of the mesoporous film with the protective nitride film denoted by $\Delta T_{\text {tot }}$, i.e.

$$
\Delta T_{\mathrm{f}}=\Delta T_{\text {tot }}-\Delta T_{\text {ref }}
$$

Figure 5 shows typical amplitudes of temperature oscillation per unit power $\Delta T_{\text {ref }} / P$ and $\Delta T_{\text {tot }} / P$ as a function of frequency at temperatures 66 and $295 \mathrm{~K}$, respectively. The difference in $\Delta T_{\mathrm{f}} /$ $P$ between the sample and the reference appeared to be independent of frequency and was used to calculate the mesoporous thin film thermal conductivity $k_{\mathrm{f}}$ according to ref 34

$$
k_{\mathrm{f}}=\frac{P t_{\mathrm{f}}}{2 b L \Delta T_{\mathrm{f}}}
$$

where $t_{\mathrm{f}}$ is the thickness of the mesoporous film while $2 b$ and $L$ are the width and length of the aluminum metallic heater, respectively. Note that the random error associated with $k_{\mathrm{f}}$ was estimated to be 


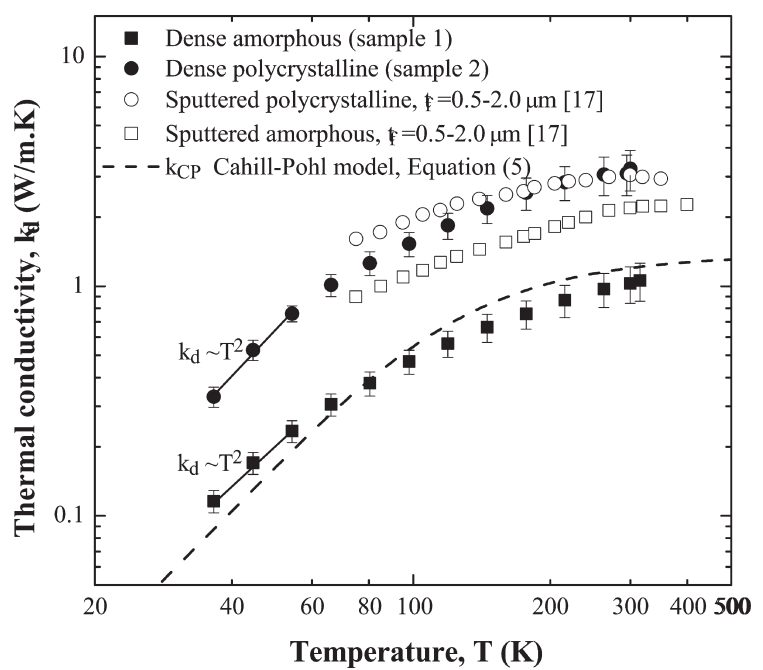

Figure 8. Measured thermal conductivity of sol-gel-derived nontemplated (dense) amorphous and polycrystalline $\mathrm{TiO}_{2}$ thin films as a function of temperature between 30 and $320 \mathrm{~K}$ along with previously reported data ${ }^{17}$ and predictions by the Cahill-Pohl model (eq 5).

less than $0.005 \mathrm{~W} / \mathrm{m} \cdot \mathrm{K}$ by performing at least three independent measurements for each temperature. Error propagation analysis was performed to estimate the overall uncertainty associated with the measured thermal conductivity $k_{\mathrm{f}}(T)$ computed using eqs $1-4$.

2.5. Validation. The experimental apparatus was first validated by measuring the thermal conductivity of high purity single crystal silicon substrate and thermally grown amorphous silicon dioxide (thermal oxide) films. Figure 6 compares the measured thermal conductivity of high purity single crystal silicon substrate as a function of temperature with data reported in the literature. ${ }^{35,36}$ Good agreement (within 10\%) was found between the present and reported data. ${ }^{35}$ In addition, the thermal conductivity for B- or Sb-doped silicon reported by Lee and Cahill ${ }^{36}$ was smaller than those measured in the present study. This can be attributed to phonon scattering by the dopant atoms.

Moreover, Figure 7 shows the thermal conductivity of $1.2 \mu \mathrm{m}$ thick thermal oxide film as a function of temperature between 30 and $320 \mathrm{~K}$. The experimental uncertainty for each data point was estimated to be smaller than $0.05 \mathrm{~W} / \mathrm{m} \cdot \mathrm{K}$. The maximum and average relative difference between the present study and the previous results for $0.99 \mu \mathrm{m}$ thick thermal oxide ${ }^{15}$ and bulk amorphous silica (Vitreosil) ${ }^{25}$ were $9 \%$ and $6 \%$, respectively. This also confirms that when the silica film is thicker than $1 \mu \mathrm{m}$, the apparent thermal conductivity is approximately that of bulk silica. $^{15,37}$ The slight difference among different data sets could be attributed to the difference in silica density and composition (impurities).

Overall, the experimental setup and the associated analysis were in good agreement with experimental data reported in the literature for high purity single crystal silicon ${ }^{35}$ and thermal oxide ${ }^{15}$ between 30 and $320 \mathrm{~K}$. Therefore, the experimental setup and procedure can be utilized to measure the thermal conductivity of the dense or mesoporous, amorphous, or polycrystalline $\mathrm{TiO}_{2}$ thin films previously described.

\section{RESULTS AND DISCUSSION}

3.1. Dense Amorphous and Polycrystalline Titania Thin Films. Experimental Results. Figure 8 shows the measured thermal conductivity of sol-gel-derived nontemplated (referred to as dense) polycrystalline and amorphous $\mathrm{TiO}_{2}$ thin films as a function of temperature between 30 and $320 \mathrm{~K}$. The average experimental uncertainty for both films was about $14 \%$. Figure 8 indicates that the thermal conductivity of the polycrystalline and amorphous dense films denoted by $k_{\mathrm{d}}(T)$ increased monotonically with increasing temperature. By contrast, the thermal conductivity of bulk dense crystalline materials typically decreases with increasing temperature for temperatures larger than $T_{\text {debye }} / 10$ due to phonon Umklapp scattering. ${ }^{38}$ Note that the Debye temperature $T_{\text {debye }}$ for anatase is about $500 \mathrm{~K}^{39}$ Therefore, the present observations suggest that phonon scattering by crystalline grains and film boundaries dominates over phonon Umklapp scattering in the polycrystalline dense $\mathrm{TiO}_{2}$ film. In addition, the measured thermal conductivity of both polycrystalline and amorphous films varied as $T^{2}$ for low temperatures between 30 and $60 \mathrm{~K}$. Moreover, the thermal conductivity of the polycrystalline film (sample 2) was about three times larger than that of the amorphous film (sample 1) for any given temperature. This was mainly due to the fact that, in amorphous materials, heat is transferred mainly by localized lattice vibrations as opposed to phonons with relatively long mean free path in crystalline materials. ${ }^{26}$

Figure 8 also shows the thermal conductivity of sputtered polycrystalline and amorphous $\mathrm{TiO}_{2}$ thin films between 80 and $400 \mathrm{~K}$ reported by Lee et al. ${ }^{17}$ The sputtered polycrystalline $\mathrm{TiO}_{2}$ thin film had average grain size of about $8 \mathrm{~nm}$ and film thickness between 0.5 and $2.0 \mu \mathrm{m} .{ }^{17}$ It is evident that the thermal conductivity of the sol-gel dense polycrystalline film (sample 2) was similar to that of the sputtered polycrystalline film. ${ }^{17}$ However, the thermal conductivity of the sputtered amorphous film was about two times larger than that of the sol-gel dense amorphous film (sample 1). This difference suggests that these films may have different density and/or compositions caused by the very different synthesis processes. For example, dense titania thin films prepared by the sol-gel method usually have lower density than sputtered films. ${ }^{24}$ In addition, sol-gel derived amorphous titania often contains additional hydroxyl groups, compared with sputtered titania, ${ }^{40}$ which result in the stoichiometry $\mathrm{TiO}_{x}$ with $x>2$.

Comparison with Model for Strongly Disordered Materials. Einstein ${ }^{41}$ proposed a model for heat conduction in amorphous solids. He assumed that (i) all atoms vibrated as harmonic oscillators at the same frequency and (ii) the phase of neighboring oscillators were uncorrelated. ${ }^{38}$ Cahill and Pohl ${ }^{38}$ improved this model by considering the coherence of a crystal wave over a distance on the order of a mean free path. The Cahill-Pohl model divided a solid into localized regions of size $\lambda / 2$, where $\lambda$ is the wavelength of a given phonon mode, and assumed that these localized regions vibrate at frequencies equal to $\omega=2 \pi v_{s} / \lambda$, where $v_{\mathrm{s}}$ is the speed of sound. ${ }^{42,43}$ Based on these assumptions, the thermal conductivity of a strongly disordered material as a function of temperature was expressed as ${ }^{42}$

$$
k_{C P}(T)=\left(\frac{\pi}{6}\right)^{1 / 3} k_{\mathrm{B}} n^{2 / 3} \sum_{i=1}^{3} v_{\mathrm{si}}\left(\frac{T}{\theta_{i}}\right)^{2} \int_{0}^{\theta_{i} / T} \frac{x^{3} \mathrm{e}^{x}}{\left(\mathrm{e}^{x}-1\right)^{2}} \mathrm{~d} x
$$

where $k_{\mathrm{B}}=1.38 \times 10^{-23} \mathrm{~m}^{2} \mathrm{~kg} / \mathrm{s}^{2} \mathrm{~K}$ is the Boltzmann constant and $n$ is the number of atoms per unit volume of material. Summation is performed over three polarizations including two transverse and one longitudinal polarization with associated 


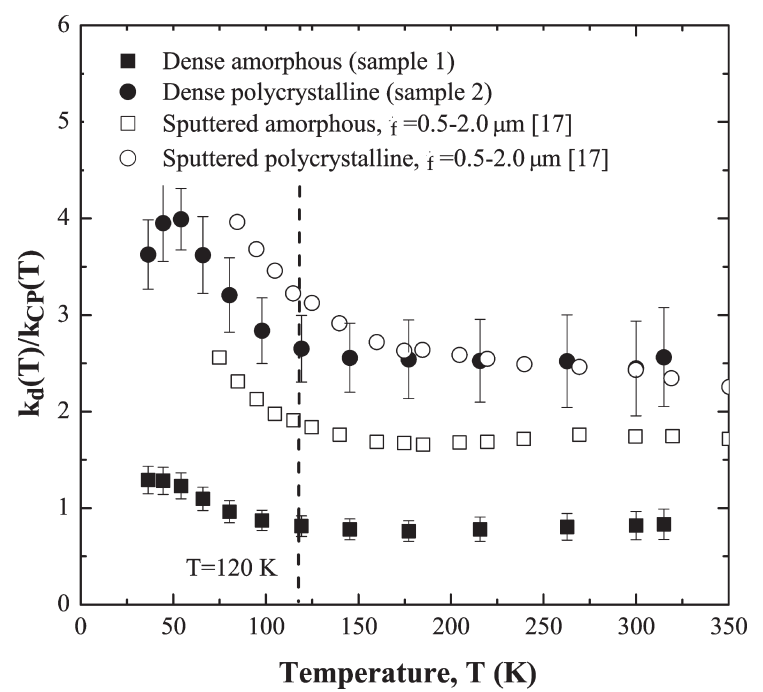

Figure 9. Ratio $k_{\mathrm{d}}(T) / k_{\mathrm{CP}}(T)$ as a function of temperature between 30 and $320 \mathrm{~K}$ for sputtered ${ }^{17}$ and sol-gel derived dense $\mathrm{TiO}_{2}$ thin films. $k_{\mathrm{d}}(T)$ was shown in Figure 8, and $k_{\mathrm{CP}}(T)$ was predicted from eq 5.

speed of sound $v_{\mathrm{si}}$ and characteristic temperature $\theta_{i}=v_{\mathrm{si}}\left(\hbar / k_{\mathrm{B}}\right)$ $\left(6 \pi^{2} n\right)^{1 / 3}$. The Cahill-Pohl model has been termed the minimum thermal conductivity model for amorphous and strongly disordered polycrystalline materials. ${ }^{38}$ Here, the average speed of sound $v_{\mathrm{s}}=4140 \mathrm{~m} / \mathrm{s}$ for anatase $\mathrm{TiO}_{2}$ was used for all three polarizations. ${ }^{39}$ The atom number per unit volume was taken as $n$ $=2.94 \times 10^{28} \mathrm{~m}^{-3}$ according to measurements by Lee et al. ${ }^{17}$ for sputtered amorphous $\mathrm{TiO}_{2}$. As previously mentioned, the actual atom number per unit volume in dense sol-gel films may be smaller. ${ }^{24}$ The minimum thermal conductivity of strongly disordered $\mathrm{TiO}_{2}$ predicted by eq 5 was also plotted in Figure 8 (dashed line). It is evident that the minimum predictions by the model were close to the measured thermal conductivity of sol-gel dense amorphous $\mathrm{TiO}_{2}$ thin film (sample 1). This could be attributed to its amorphous phase as well as to the small porosity resulting from the sol-gel process, as previously mentioned. As expected, the model predictions were smaller than $k_{\mathrm{d}}$ measured for all other dense $\mathrm{TiO}_{2}$ thin films.

In order to compare the temperature dependence of the measured thermal conductivity with that predicted by eq 5 , Figure 9 plots the ratio $k_{\mathrm{d}}(T) / k_{\mathrm{CP}}(T)$ as a function of temperature. It indicates that for $T>120 \mathrm{~K}, k_{\mathrm{d}}(T) / k_{\mathrm{CP}}(T)$ was nearly independent of temperature for dense sputtered as well as for sol-gel amorphous and polycrystalline $\mathrm{TiO}_{2}$ thin films. It establishes that the Cahill-Pohl model successfully captured the temperature dependence of the thermal conductivity of both amorphous and polycrystalline dense sol-gel films. On the other hand, for $T<120 \mathrm{~K}$, the ratio $k_{\mathrm{d}}(T) / k_{\mathrm{CP}}(T)$ increased as temperature decreased. The discrepancy between the measured and predicted thermal conductivity at low temperatures was also observed by Cahill and Poh $l^{43}$ for amorphous silica. It was attributed to the fact that the Cahill-Pohl model does not include energy transport by phonons with long mean free path whose contributions become important at low temperatures in both amorphous and strongly disordered polycrystalline solids. ${ }^{43,44}$

3.2. Mesoporous Titania Thin Films. Figure 10 shows the measured thermal conductivity as a function of temperature for the amorphous and polycrystalline, sol-gel, and NC-based, mesoporous $\mathrm{TiO}_{2}$ thin films (samples $\left.3-7\right)$, denoted by $k_{\mathrm{f}}(T)$. The average

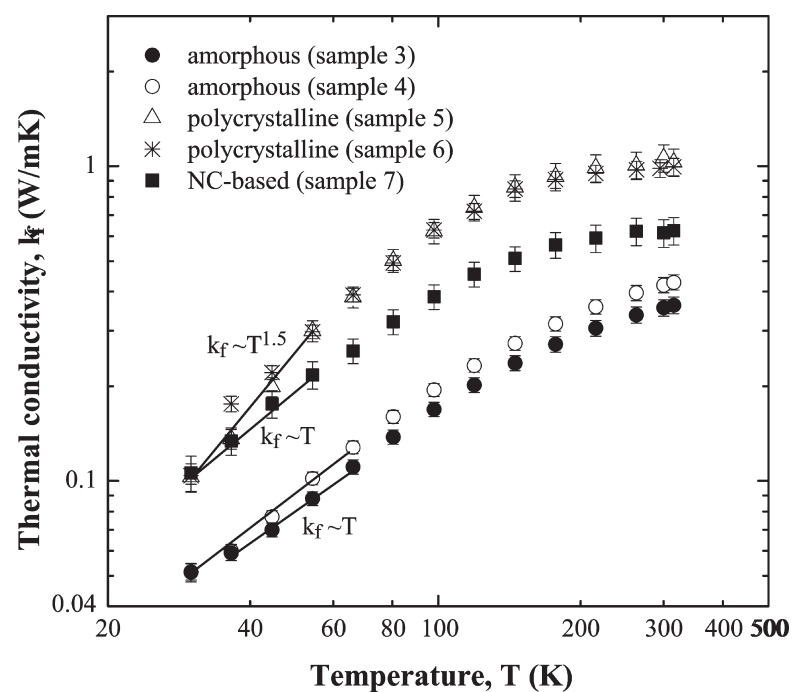

Figure 10. Measured thermal conductivity as a function of temperature between 30 and $320 \mathrm{~K}$ for block copolymer templated sol-gel (samples 3-6) and NC-based (sample 7) mesoporous $\mathrm{TiO}_{2}$ thin films.

experimental uncertainty was between 5 and $11 \%$ for all films between 30 and $320 \mathrm{~K}$. Note that the thermal conductivity of the mesoporous $\mathrm{TiO}_{2}$ thin films measured at room temperature agreed well with previous results reported by Coquil et al. ${ }^{20}$ This confirms their assumptions that heat losses to the surroundings by conduction and convection were negligible in their experiments.

Sol-Gel Amorphous Mesoporous TiO 2 Thin Films. Figure 10 indicates that the thermal conductivity of sol-gel amorphous mesoporous $\mathrm{TiO}_{2}$ thin films (samples 3 and 4) increased with increasing temperature. It was less than half of that for the amorphous dense film, for all temperatures. The reduction in thermal conductivity of the amorphous mesoporous $\mathrm{TiO}_{2}$ thin films was mainly due to the facts that (i) in amorphous materials heat is transferred by very localized nonpropagating vibrational modes and (ii) the cross-sectional area for heat transfer through the film is reduced by the presence of the pores. ${ }^{26}$ In addition, the thermal conductivity of sample 4 was slightly larger than that of sample 3 for all temperatures with a maximum absolute difference less than or comparable to the experimental uncertainty. This could be attributed to variations in morphology from one sample to another.

Moreover, the thermal conductivity of amorphous mesoporous $\mathrm{TiO}_{2}$ thin films was proportional to $T$ for temperature $T<60$ $\mathrm{K}$ as opposed to $T^{2}$ for the corresponding dense film (sample 1 ). This could be due to the fact that the presence of mesopores reduces the contribution, to heat transfer, of phonon modes with long mean free path. This, in turn, makes the thermal conductivity less temperature dependent.

Finally, Figure 11 plots the ratios of the thermal conductivity $k_{\mathrm{f}}(T)$ of samples 3 and 4 (Figure 10) to that of dense sample 1 denoted by $k_{\mathrm{d}}(T)$ (Figure 8 ) as a function of temperature. They were found to be equal to 0.35 and 0.41 and independent of temperature between 60 and $320 \mathrm{~K}$. This confirms the observations made by Shin et al. ${ }^{27}$ on mesoporous amorphous $\mathrm{SiO}_{2}$ films indicating that the presence of the pores in amorphous materials had a purely geometrical effect and did not affect the localized vibrational modes. Then, the temperature dependence of $k_{\mathrm{f}}(T)$ was captured by that of the continuous amorphous phase denoted by $k_{\mathrm{d}}(T)$. Thus, for $T>60 \mathrm{~K}$, the thermal conductivity 


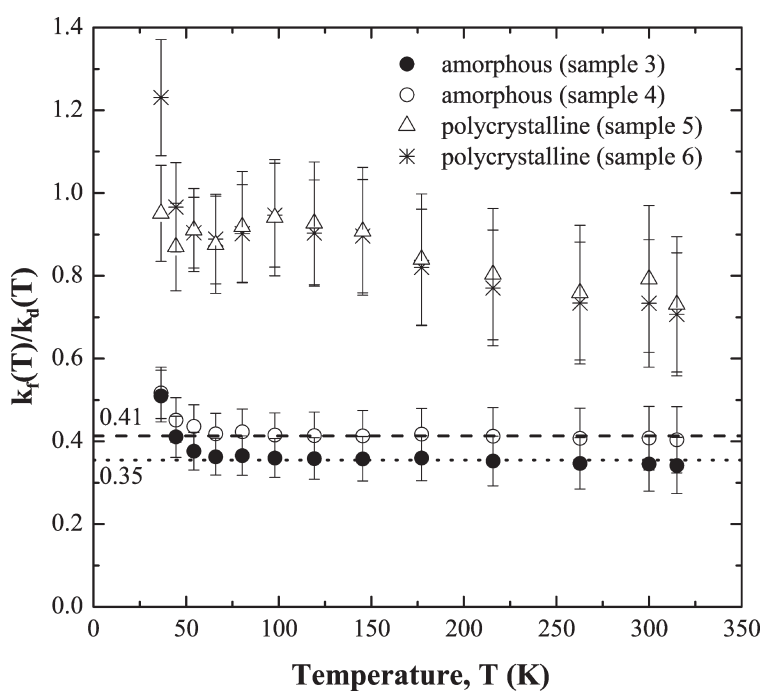

Figure 11. Ratio of measured thermal conductivity of sol-gel-derived KLE-templated mesoporous films $k_{\mathrm{f}}(T)$ (Figure 10) to that of the corresponding dense film $k_{\mathrm{d}}(T)$ as a function of temperature between 30 and $320 \mathrm{~K}$. Here, $k_{\mathrm{d}}(T)$ was taken as $(\mathrm{i}) k_{\mathrm{d}}(T)$ measured for sample 1 in the case of samples 3 and 4 and (ii) $k_{\mathrm{d} 2}(T)$ given by eq 8 in the case of samples 5 and 6.

of the amorphous mesoporous films $k_{\mathrm{f}}(T)$ can be expressed as a function of $k_{\mathrm{d}}(T)$ and a geometric parameter such as porosity $f_{\mathrm{v}}$ using some effective medium approximation. For $T<60 \mathrm{~K}$, the ratios increased with decreasing temperature. This is due to the fact that, at low temperatures, the thermal conductivity of the mesoporous amorphous films is less temperature dependent $\left(k_{\mathrm{f}} \propto T\right)$ than that of the dense amorphous film $\left(k_{\mathrm{d}} \propto T^{2}\right)$, as previously discussed.

Sol-Gel Polycrystalline Mesoporous $\mathrm{TiO}_{2}$ Thin Films. Figure 10 indicates that the sol-gel polycrystalline mesoporous $\mathrm{TiO}_{2}$ thin films (samples 5 and 6 ) featured thermal conductivity approximately one-third as large as that of the dense polycrystalline thin film (sample 2) from 30 to $320 \mathrm{~K}$ shown in Figure 8. This reduction can be attributed to phonon scattering by pores and by smaller crystalline domains. In fact, the crystalline domain sizes were $12-13 \mathrm{~nm}$ in size in sol-gel polycrystalline mesoporous films (samples 5 and 6) as opposed to $30 \mathrm{~nm}$ in their dense counterpart (sample 2). The difference in thermal conductivity between the two porous samples ( 5 and 6) was less than the experimental uncertainty for all temperatures.

Figure 10 shows that the thermal conductivity of sol-gel polycrystalline mesoporous $\mathrm{TiO}_{2}$ thin films (samples 5 and 6) varied as $T^{1.5}$ for temperatures below $60 \mathrm{~K}$ as opposed to $T^{2}$ for the corresponding dense film (sample 2). In addition, the thermal conductivity of polycrystalline mesoporous $\mathrm{TiO}_{2}$ thin films reached a constant value of about $1.0 \mathrm{~W} / \mathrm{m} \cdot \mathrm{K}$ for temperatures larger than $300 \mathrm{~K}$. This suggests that nearly all phonon modes were excited above $300 \mathrm{~K}$. Note that such a plateau was not observed at high temperatures for the polycrystalline dense $\mathrm{TiO}_{2}$ film.

The effect of the presence of the pores was further investigated by comparing the thermal conductivity of the polycrystalline mesoporous $\mathrm{TiO}_{2}$ thin film with that of the equivalent dense film. To account for the effect of crystalline domain size, Smith and co-workers ${ }^{45,46}$ expressed the total thermal resistance of polycrystalline material as the sum of the thermal resistance of the equivalent single crystal and that of all grain boundaries in series as

$$
\frac{1}{k_{\mathrm{d}}(T)}=\frac{1}{k_{\text {crystal }}(T)}+\frac{R_{\text {int }}(T)}{d_{\mathrm{g}}}
$$

where $k_{\text {crystal }}$ is the thermal conductivity of bulk single crystal, $R_{\text {int }}$ is the thermal resistance of a single grain boundary, and $d_{\mathrm{g}}$ is the average grain size. This model was adopted to predict the thermal conductivities $k_{\mathrm{d} 1}$ and $k_{\mathrm{d} 2}$ of bulk dense polycrystalline anatase $\mathrm{TiO}_{2}$ with grain size $d_{\mathrm{g} 1}=30 \mathrm{~nm}$ and $d_{\mathrm{g} 2}=13 \mathrm{~nm}$, respectively. Hence, the ratio $k_{\mathrm{d} 2} / k_{\mathrm{d} 1}$ can be expressed as

$$
\frac{k_{\mathrm{d} 2}(T)}{k_{\mathrm{d} 1}(T)}=\frac{1+k_{\text {crystal }}(T) R_{\text {int }}(T) / d_{\mathrm{g} 1}}{1+k_{\text {crystal }}(T) R_{\text {int }}(T) / d_{\mathrm{g} 2}}
$$

To the best of our knowledge, the thermal conductivity $k_{\text {crystal }}(T)$ of bulk single crystal anatase as a function of temperature is not available in the literature. However, the thermal conductivity of rutile, another polymorph of $\mathrm{TiO}_{2}$, was reported between 1 and $400 \mathrm{~K}^{37} \mathrm{It}$ decreases with increasing temperature above $15 \mathrm{~K}$ and is 11.7 and $8.5 \mathrm{~W} / \mathrm{m} \cdot \mathrm{K}$ at $300 \mathrm{~K}$ for bulk single crystal and polycrystalline rutile, respectively. ${ }^{37} \mathrm{We}$ expect it to be similar for anatase phase. In addition, the thermal resistance $R_{\text {int }}(T)$ of a crystalline grain boundary is typically on the order of $10^{-8} \mathrm{~m}^{2} \cdot \mathrm{K} / \mathrm{W}$. $^{45}$ Therefore, for $d_{\mathrm{g}} \sim 10 \mathrm{~nm} k_{\text {crystal }} R_{\text {int }} / d_{\mathrm{g}}$ is on the order of 10 at room temperature. For lower temperatures, this term should increase due to significant increase in $k_{\text {crystal }}$ $(T)^{37}$ and only moderate change in $R_{\text {int }}(T){ }^{45}$ Thus, as a first order approximation, the ratio $k_{\mathrm{d} 2}(T) / k_{\mathrm{d} 1}(T)$ simplifies as

$$
\frac{k_{\mathrm{d} 2}(T)}{k_{\mathrm{d} 1}(T)}=\frac{d_{\mathrm{g} 2}}{d_{\mathrm{g} 1}}
$$

Here, the thermal conductivity $k_{\mathrm{d} 2}(T)$ of dense polycrystalline $\mathrm{TiO}_{2}$ with grain size $d_{\mathrm{g} 2}=13 \mathrm{~nm}$ was calculated by substituting $k_{\mathrm{d} 1}(T)$ with measured data for sample 2 whose grain size was $d_{\mathrm{g} 1}=30 \mathrm{~nm}$. Figure 11 also plots the ratios of the thermal conductivity of samples 5 and 6 to that of $k_{\mathrm{d} 2}$ as a function of temperature. Unlike for amorphous mesoporous samples, the ratios fluctuate with temperature and no clear trend is apparent. This can be attributed to the presence of the pores which affect the phonon dispersion and density of states possibly due to the quantum confinement effect. ${ }^{47}$

Nanocrystal-Based Mesoporous $\mathrm{TiO}_{2}$ Thin Film. Figure 10 shows that the thermal conductivity of the NC-based mesoporous $\mathrm{TiO}_{2}$ thin film (sample 7) was $40 \%$ less than that of the sol-gel polycrystalline mesoporous thin films (samples 5 and 6). This was due to the facts that (i) the nanocrystals contacted each other over very small surface area with additional microporosity stemming from the space between them, ${ }^{20}$ (ii) the anatase nanocrystal size was $9 \mathrm{~nm}$ as opposed to $12-13 \mathrm{~nm}$ for the polycrystalline domain of sol-gel films, and (iii) NC-based mesoporous films had porosity of $35 \%$ instead of $30 \%$ for the sol-gel films. This poorly connected nanostructure caused significant phonon scattering at the interfaces between nanocrystals. On the other hand, the thermal conductivity of the NCbased film was about two times larger than that of sol-gel amorphous mesoporous films (samples 3 and 4) for all temperatures, despite their larger porosity. This can be attributed to the crystallinity of the NC-based mesoporous film.

In addition, the trend of thermal conductivity of the NC-based mesoporous $\mathrm{TiO}_{2}$ thin film with respect to temperature indicates 
that both the crystalline nature of nanocrystals and the loosely connected porous structure affected its thermal conductivity. On the one hand, at low temperatures, its thermal conductivity was linearly proportional to temperature $T$ as observed for amorphous mesoporous films (samples 3 and 4). On the other hand, its thermal conductivity reached a plateau beyond $300 \mathrm{~K}$ as observed for polycrystalline mesoporous films (samples 5 and 6), suggesting saturated phonon modes in the NC-based mesoporous $\mathrm{TiO}_{2}$ film.

\section{CONCLUSION}

This paper presented measurements of the cross-plane thermal conductivity of mesoporous $\mathrm{TiO}_{2}$ thin films between 30 and $320 \mathrm{~K}$. Amorphous and crystalline as well as sol-gel derived and nanocrystal-based mesoporous $\mathrm{TiO}_{2}$ thin films were investigated. The following conclusions can be drawn:

1 The thermal conductivity of sol-gel derived $\mathrm{TiO}_{2}$ thin films increased with increasing temperature. For amorphous and polycrystalline mesoporous $\mathrm{TiO}_{2}$ thin films, conductivity at low temperatures was proportional to $T$ and $T^{1.5}$, respectively, as opposed to $T^{2}$ for the corresponding nontemplated (dense) films.

2 The Cahill-Pohl model for highly disordered materials captured the temperature dependence of the thermal conductivity of dense amorphous and polycrystalline $\mathrm{TiO}_{2}$ thin films for $T>120 \mathrm{~K}$.

3 The sol-gel amorphous mesoporous $\mathrm{TiO}_{2}$ thin films had thermal conductivity less than half of that of their dense counterpart. The thermal conductivity of amorphous dense and mesoporous films had similar temperature dependence for $T>60 \mathrm{~K}$. This was due to the fact that the presence of the pores only reduces the cross-sectional area for heat transport without affecting the localized vibrational modes.

4 The thermal conductivity of sol-gel polycrystalline mesoporous $\mathrm{TiO}_{2}$ thin films was three times smaller than that of their dense counterpart. This was mainly due to phonon scattering by pores and smaller crystalline domains $(12-13$ versus $30 \mathrm{~nm}$ ). The thermal conductivity of polycrystalline dense and mesoporous films had different temperature dependence suggesting that the presence of the pores also affect the phonon dispersion and density of state in the polycrystalline matrix.

5 The NC-based mesoporous $\mathrm{TiO}_{2}$ film had thermal conductivity about $40 \%$ less than that of the polycrystalline mesoporous films and two times larger than that of the amorphous mesoporous films. This was attributed to its particles' crystallinity with smaller crystal size $(\sim 9 \mathrm{~nm})$, larger porosity $(35 \%)$, and poor connections between individual anatase nanocrystals.

\section{AUTHOR INFORMATION}

\section{Corresponding Author}

*Phone +1 (310)-206-5598; fax +1 (310)-206-4830; e-mail pilon@seas.ucla.edu.

\section{ACKNOWLEDGMENT}

This material is based upon work supported by the National Science Foundation under Grant CTS 0449429 (L.P.) and CHE0527015 (S.H.T) and by the Intel/NERC/UC Discovery Program. T.B. acknowledges the support of a Liebig Fellowship by the Fonds der Chemischen Industrie im Verband der Chemischen Industrie.

\section{REFERENCES}

(1) Wang, J.; Polleux, J.; Lim, J.; Dunn, B. Pseudocapacitive contributions to electrochemical energy storage in $\mathrm{TiO}_{2}$ (anatase) nanoparticles. J. Phys. Chem. C 2007, 111 (40), 14925-14931.

(2) Brezesinski, T.; Wang, J.; Polleux, J.; Dunn, B.; Tolbert, S. H. Templated nanocrystal-based porous $\mathrm{TiO}_{2}$ films for next-generation electrochemical capacitors. J. Am. Chem. Soc. 2009, 131 (5), 1802-1809.

(3) O’Regan, B.; Grätzel, M. A low-cost, high-efficiency solar cell based on dye-sensitized colloidal $\mathrm{TiO}_{2}$ films. Nature 1991, 353, $737-740$.

(4) Ekström, H.; Wickman, B.; Gustavsson, M.; Hanarp, P.; Eurenius, L.; Olsson, E.; Lindbergh, G. Nanometer-thick films of titanium oxide acting as electrolyte in the polymer electrolyte fuel cell. Electrochim. Acta 2007, 52 (12), 4239-4245.

(5) Leroux, F.; Dewar, P. J.; Intissar, M.; Ouvrard, G.; Nazarb, L. Study of the formation of mesoporous titania via a template approach and of subsequent Li insertion. J. Mater. Chem. 2002, 12, 3245-3253.

(6) Choi, S. G.; Ha, T.-J.; Yu, B.-G.; Shin, S.; Cho, H. H.; Park, H.-H. Application of mesoporous $\mathrm{TiO}_{2}$ as a thermal isolation layer for infrared sensors. Thin Solid Films 2007, 516 (2-4), 212-215.

(7) Wang, K.; Morris, M. A.; Holmes, J. D. Preparation of mesoporous titania thin films with remarkably high thermal stability. Chem. Mater. 2005, 17 (6), 1269-1271.

(8) Hoffmann, M. R.; Martin, S. T.; Choi, W.; Bahnemann, D. W. Environmental applications of semiconductor photocatalysis. Chem. Rev. 1995, 95 (1), 69-96.

(9) Negishi, N.; Iyoda, T.; Hashimoto, K.; Fujishima, A. Preparation of transparent $\mathrm{TiO}_{2}$ thin film photocatalyst and its photocatalytic activity. Chem. Lett. 1995, 24 (9), 841.

(10) Vogel, R.; Meredith, P.; Kartini, I.; Harvey, M.; Riches, J. D.; Bishop, A.; Heckenberg, N.; Trau, M.; Rubinsztein-Dunlop, H. Mesostructured dye-doped titanium dioxide for micro-optoelectronic applications. ChemPhysChem 2003, 4 (6), 595-603.

(11) Kay, A.; Grätzel, M. Low cost photovoltaic modules based on dye sensitized nanocrystalline titanium dioxide and carbon powder. Sol. Energy Mater. Sol. Cells 1996, 44 (1), 99-117.

(12) Yang, H.; Yu, C.; Song, Q.; Xia, Y.; Li, F.; Chen, Z.; Li, X.; Yi, T.; Huang, C. High-temperature and long-term stable solid-state electrolyte for dye-sensitized solar cells by self-assembly. Chem. Mater. 2006, 18 (22), 5173-5177.

(13) Miller, J. R. Electrochemical capacitor thermal management issues at high-rate cycling. Electrochim. Acta 2006, 52 (4), 1703-1708.

(14) Guillemet, P.; Scudeller, Y.; Brousse, T. Multi-level reducedorder thermal modeling of electrochemical capacitors. J. Power Sources 2006, 157 (1), 630-640.

(15) Cahill, D. G.; Allen, T. H. Thermal conductivity of sputtered and evaporated $\mathrm{SiO}_{2}$ and $\mathrm{TiO}_{2}$ optical coatings. Appl. Phys. Lett. 1994, 65 (3), 309-311.

(16) Mun, J.; Kim, S. W.; Kato, R.; Hatta, I.; Lee, S. H.; Kang, K. H. Measurement of the thermal conductivity of $\mathrm{TiO}_{2}$ thin films by using the thermo-reflectance method. Thermochim. Acta 2007, 455 (1-2), 55-59.

(17) Lee, S.-M.; Cahill, D. G.; Allen, T. H. Thermal conductivity of sputtered oxide films. Phys. Rev. B 1995, 52 (1), 253-257.

(18) Kim, D. J.; Kim, D. S.; Cho, S.; Kim, S. W.; Lee, S. H.; Kim, J. C. Measurement of thermal conductivity of $\mathrm{TiO}_{2}$ thin films using $3 \omega$ method. Int. J. Thermophys. 2004, 25 (1), 281-289.

(19) Feng, X.; Wang, X.; Chen, X.; Yue, Y. Thermo-physical properties of thin films composed of anatase $\mathrm{TiO}_{2}$ nanofibers. Acta Mater. 2010, 59 (5), 1934-1944.

(20) Coquil, T.; Reitz, C.; Brezesinski, T.; Nemanick, E. J.; Tolbert, S. H.; Pilon, L. Thermal conductivity of mesoporous titania films made from nanocrystalline building blocks and sol-gel reagents. J. Phys. Chem. C 2010, 114 (29), 12451-12458.

(21) Fattakhova-Rohlfing, D.; Wark, M.; Brezesinski, T.; Smarsly, B. M.; Rathousky, J. Highly organized mesoporous $\mathrm{TiO}_{2}$ films with controlled crystallinity: A Li-insertion study. Adv. Funct. Mater. 2007, $17,123-132$. 
(22) Brezesinski, K.; Wang, J.; Haetge, J.; Reitz, C.; Tolbert, S. H.; Smarsly, B. M.; Dunn, B.; Brezesinski, T. Pseudocapacitive contributions to charge storage in highly ordered mesoporous group $\mathrm{V}$ transition metal oxides with iso-oriented layered nanocrystalline domains. J. Am. Chem. Soc. 2010, 132 (20), 6982-6990.

(23) Brezesinski, K.; Haetge, J.; Wang, J.; Mascotto, S.; Reitz, C.; Rein, A.; Tolbert, S. H.; Perlich, J.; Dunn, B.; Brezesinski, T. Ordered mesoporous $\alpha-\mathrm{Fe}_{2} \mathrm{O}_{3}$ (hematite) thin film electrodes for application in high rate rechargeable lithium batteries. Small 2011, 7 (3), 407-414.

(24) Fan, Q.; McQuillin, B.; Ray, A. K.; Turner, M. L.; Seddon, A. B. High density, non-porous anatase titania thin films for device applications. J. Phys. D: Appl. Phys. 2000, 33 (21), 2683-2686.

(25) Cahill, D. G. Thermal conductivity measurement from 30 to $750 \mathrm{~K}$ : The $3 \omega$ method. Rev. Sci. Instrum. 1990, 61 (2), $802-808$.

(26) Coquil, T.; Richman, E. K.; Hutchinson, N. J.; Tolbert, S. H.; Pilon, L. Thermal conductivity of cubic and hexagonal mesoporous silica thin films. J. Appl. Phys. 2009, 106 (3), 034910 1-11.

(27) Shin, S.; Ha, T.-J.; Park, H.-H.; Cho, H. H. Thermal conductivity of BCC-ordered mesoporous silica films. J. Phys. D: Appl. Phys. 2009, 42 (12), 125404 1-5.

(28) Hu, C.; Morgen, M.; Ho, P. S. Thermal conductivity study of porous low-k dielectric materials. Appl. Phys. Lett. 2000, 72 (1), $145-147$.

(29) Song, D. W.; Shen, W.-N.; Dunn, B.; Moore, C. D.; Goorsky, M. S.; Radetic, T.; Gronsky, R.; Chen, G. Thermal conductivity of nanoporous bismuth thin films. Appl. Phys. Lett. 2004, 84 (11), 1883-1885.

(30) Jousseaume, V.; Fayolle, M.; Guedj, C.; Haumesser, P. H.; Huguet, C.; Pierre, F.; Pantel, R.; Feldis, H.; Passemard, G. Pore sealing of a porous dielectric by using a thin PECVD a-SiC:H conformal liner. J. Electrochem. Soc. 2005, 152 (10), 156-161.

(31) Ziman, J. M. Electron and Phonons; Oxford University Press, Oxford, U.K., 1960.

(32) Chen, Z.; Jang, W.; Bao, W.; Lau, C. N.; Dames, C. Thermal contact resistance between graphene and silicon dioxide. Appl. Phys. Lett. 2009, 95 (161910), $1619101-3$.

(33) Nelder, J. A.; Mead, R. A simplex method for function minimization. Comput. J. 1965, 7 (4), 308-313.

(34) Cahill, D. G.; Katiyar, M.; Abelson, J. R. Thermal conductivity of a-Si:H thin films. Phys. Rev. B 1994, 50 (9), 6077-6081.

(35) Glassbrenner, C. J.; Slack, G. A. Thermal conductivity of silicon and germanium from 3 K to the melting point. Phys. Rev. 1964, 134 (4A), A1058-A1069.

(36) Lee, S. M.; Cahill, D. G. Heat transport in thin dielectric films. J. Appl. Phys. 1997, 81 (6), 2590-2595.

(37) Touloukian, Y. S.; Powell, R. W.; Ho, C. Y.; Klemens, P. G. Thermophysical properties of matter-thermal conductivity of nonmetallic solids. TPRC Data Series, Vol. 2; IFI/Plenum: New York, 1970.

(38) Tien, C. L.; Majumdar, A.; Gerner, F. M. Microscale Energy Transport; Taylor and Francis: Washington, DC, 1998.

(39) Shojaee, E.; Mohammadizadeh, M. R. First-principles elastic and thermal properties of $\mathrm{TiO}_{2}$ : A phonon approach. J. Phys.: Condens. Matter 2010, 22 (1), 1-8.

(40) Lopez, T.; Ortiz-Islas, E.; Vinogradova, E.; Manjarrez, J.; Azamar, J. A.; Alvarado-Gil, J. J.; Quintana, P. Structural, optical and vibrational properties of sol-gel titania valproic acid reservoirs. Opt. Mater. 2006, 29 (1), 82-87.

(41) Einstein, A. Elementare betrachtungen über die thermische molekularbewegung in festen körpern. Ann. Phys. 1911, 35, 679.

(42) Cahill, D. G.; Pohl, R. O. Lattice vibrations and heat transport in crystals and glasses. Annu. Rev. Phys. Chem. 1988, 39, 93-121.

(43) Cahill, D. G.; Pohl, R. O. Heat flow and lattice vibrations in glasses. Solid State Commun. 1989, 70 (10), 927-930.

(44) Pohl, R. O. Lattice vibrations of glass. J. Non-Cryst. Solids 2006, $352(32-35), 3363-3367$.
(45) Smith, D. S.; Fayette, S.; Grandjean, S.; Martin, C. Thermal resistance of grain boundaries in alumina ceramics and refractories. J. Am. Ceram. Soc. 2003, 86 (1), 105-111.

(46) Nait-Ali, B.; Haberko, K.; Vesteghem, H.; Absi, J.; Smith, D. S. Thermal conductivity of highly porous zirconia. J. Eur. Ceram. Soc. 2006, 26 (16), 3567-3574.

(47) Randrianalisoa, J.; Baillis, D. Monte carlo simulation of steadystate microscale phonon heat transport. ASME J. Heat Transfer 2008, 130 (7), 072404. 